\title{
Hepatocyte growth factor protects endothelial cells against gamma ray irradiation-induced damage
}

\author{
Shun-ying $\mathrm{HU}^{1}$, Hai-feng DUAN², Qing-fang $\mathrm{LI}^{2}$, Yue-feng YANG ${ }^{2}$, Jin-long $\mathrm{CHEN}^{2}$, Li-sheng WANG ${ }^{2}$, Hua WANG ${ }^{2, *}$ \\ ${ }^{1}$ Department of Cardiology, Chinese PLA General Hospital, Beijing 100853,China; ${ }^{2}$ Department of Experimental Hematology, Beijing \\ Institute of Radiation Medicine, Beijing 100850, China
}

\begin{abstract}
Aim: To investigate the effect of HGF on proliferation, apoptosis and migratory ability of human vascular endothelial cells against gamma ray irradiation.

Methods: ECV304 cells derived from adult human umbilical vein endothelial cells (HUVEC) were irradiated with a single gamma ray dose of 20 Gy. Immunocytochemistry and Western blot analysis were used to detect c-Met protein expression and HGF/c-Met signal pathway. In the HGF-treated groups, ECV304 cells were incubated with HGF (20 or $40 \mathrm{ng} / \mathrm{mL}$ ) $3 \mathrm{~h}$ prior to irradiation. At $48 \mathrm{~h}$ postirradiation, the proliferation of ECV304 cells was measured by MTT assay, the apoptosis was assessed by flow cytometry, and the migratory ability of ECV304 cells was measured by transwell chamber assay.

Results: c-Met protein is expressed in ECV304 cells and can be activated by HGF. Gamma ray irradiation inhibits proliferation and migration of ECV304 cells in a dose-dependent manner. HGF significantly promoted the proliferation of ECV304 cells, and flow cytometry revealed that HGF can inhibit apoptosis of ECV304 cells. Transwell chamber assay also showed that HGF increases migration activity of endothelial cells.

Conclusion: HGF may afford protection to vascular endothelial cells against gamma ray irradiation-induced damage.
\end{abstract}

Keywords: hepatocyte growth factor; endothelial cell; irradiation-induced damage; proliferation; apoptosis; migration

Acta Pharmacologica Sinica (2009) 30: 1415-1420; doi: 10.1038/aps.2009.133; published online 14 Sep 2009

\section{Introduction}

Radiation-induced heart disease (RIHD) is a particular problem related to radiation treatments for the mediastinum and breast, such as in lymphoma, breast cancer, esophagogastric cancer, thymoma and lung cancer ${ }^{[1]}$. The goal of radiotherapy is to deliver a dose to the tumor that is sufficient to provide a high probability of cure yet will cause minimal damage to the surrounding tissues. During radiotherapy of tumors adjacent to the heart, at least a portion of the heart is frequently included in the treatment field and may receive the full dose intended for the tumor. Local heart irradiation with single or fractionated doses leads to heart failure following dosedependent latency periods ${ }^{[2]}$. High survival rates of diseases and long follow-up time of relatively young patients revealed that irradiation of the heart can cause chronic impairment of cardiac pump function and cardiac disease ${ }^{[3-6]}$. There is compelling epidemiological evidence that the risk of dying from myocardial infarction or another ischemic heart disease is sig-

* To whom correspondence should be addressed.

E-mail wanghua@nic.bmi.ac.cn

Received 2009-06-24 Accepted 2009-07-30 nificantly increased at more than 10-15 years after exposure of the heart to local irradiation ${ }^{[7]}$.

Radiation-induced damage to the microvasculature has severe pathological implications for kidney, heart and other tissues $^{[8-10]}$. The most significant type of radiation-induced heart disease (RIHD) appears to be myocardial damage, which may result from loss of alkaline phosphatase activity of capillary endothelial cells 6-10 weeks after radiotherapy ${ }^{[9,11]}$. After a single dose of $20 \mathrm{~Gy}$, myocardial degeneration becomes apparent in rats at approximately 6 months post-irradiation and is preceded by a marked reduction in capillary density ${ }^{[12]}$. In addition to myocardial degeneration, perivascular and interstitial fibrosis are seen ${ }^{[13]}$. Parallel to the development of morphological damage, hemodynamic studies reveal a marked impairment of cardiac function ${ }^{[14,15]}$. It has been proposed that effective pharmacological intervention to protect the vascular system could lead to a decrease in normal tissue damage.

Hepatocyte growth factor (HGF), originally identified and cloned as a potent mitogen for mature hepatocytes ${ }^{[16-18]}$, has mitogenic, morphogenic, and anti-apoptotic activities in a wide variety of cells, preferentially in most epithelial and 
endothelial cells ${ }^{[19-21]}$. It is particularly important that HGF enhances regeneration of organs such as liver, kidney and lung $^{[20]}$. Additionally, HGF has angiogenic activity ${ }^{[22-24]}$.

However, whether HGF is effective in protecting vascular endothelial cells against gamma ray irradiation has not been reported. The purpose of this study was to investigate the effect of HGF on proliferation, apoptosis and migration of human vascular endothelial cells irradiated with a single dose of gamma rays.

\section{Materials and methods}

\section{Cell lines and cell culture}

ECV304 cells derived from adult human umbilical veins endothelial cells (HUVEC) were cultured in DMEM (Gibco, USA) that included $10 \%$ newborn calf serum (Gibco). The medium contained penicillin and streptomycin. Cells were incubated at $37^{\circ} \mathrm{C}$ in $5 \% \mathrm{CO}_{2}$.

\section{Immunocytochemistry}

Immunocytochemistry was used to examine expression of c-Met in the ECV304 cells. Either polyclonal rabbit antihuman c-Met IgG or the negative control of normal rabbit immunoglobulin was used as the primary antibody, and HRPlinked goat anti-rabbit IgG was used as the secondary antibody (Santa Cruz, CA, USA). Cells were visualized by a single observer with a microscope at $100 \times$ magnification.

\section{Western blot analysis}

To prepare lysates, cells were washed in PBS and solubilized with $50 \mathrm{mmol} / \mathrm{L}$ Hepes solution ( $\mathrm{pH} 7.4)$ containing 1\% (v/v) Triton X-100, $4 \mathrm{mmol} / \mathrm{L}$ EDTA, $1 \mathrm{mmol} / \mathrm{L}$ sodium fluoride, 0.1 $\mathrm{mmol} / \mathrm{L}$ sodium orthovanadate, $1 \mathrm{mmol} / \mathrm{L}$ tetrasodium pyrophosphate, $2 \mathrm{mmol} / \mathrm{L}$ phenylmethylsulfonyl fluoride (PMSF), $10 \mu \mathrm{g} / \mathrm{mL}$ leupeptin, and $10 \mu \mathrm{g} / \mathrm{mL}$ aprotitin. Following centrifugation in a microfuge, the protein concentration in the supernatant was determined. Equal protein levels of cell lysates were electrophoresed through reducing SDS polyacrylamide. Completion of the protein transfer from gels to the membranes was checked by staining the gels with Coomassie Blue R-250. The membranes were blocked with 5\% nonfat milk and incubated with antibodies for c-Met and phosphospecific c-Met. Levels of proteins and phospho-proteins were detected with HRP-linked secondary antibodies and the ECL system. Membranes were stained with Coomassie Blue to confirm that there was equal loading and transfer.

\section{Irradiation procedure}

Twenty-four $\mathrm{h}$ before irradiation, cell cultures received fresh culture medium. Cells were then irradiated at room temperature with a single dose of $20 \mathrm{~Gy}$, operated at a dose-rate of $510.4 \mathrm{cGy} / \mathrm{min}$. Sham-irradiated cell cultures were included at room temperature at the same time. After irradiation, cell cultures were replaced in the incubator and were maintained at $37^{\circ} \mathrm{C}$ under $5 \% \mathrm{CO}_{2}$.

\section{Mitogenicity bioassay (MTT test)}

A total of $200 \mu \mathrm{L}$ ECV304 cells were seeded separately into 96-well plates at a density of $1 \times 10^{6}$ cells per well. On $\mathrm{d} 3$, the cells were irradiated with a single dose of 5, 10, and $20 \mathrm{~Gy}$, respectively. At $48 \mathrm{~h}$ post-irradiation, $20 \mu \mathrm{L}$ MTT $(5 \mathrm{mg} / \mathrm{mL})$ was added to each well. The cells were cultured for an additional $4 \mathrm{~h}$, and then all the liquid in each well was tipped out. To dissolve the precipitate, $150 \mu \mathrm{L}$ DMSO was added. Absorbance at $570 \mathrm{~nm}$ was determined by ELISA spectrometry.

\section{Apoptosis assay by flow cytometry}

Flow cytometric assays for detection of apoptosis were carried out using the Annexin V kit (Caltag Laboratories) according to the manufacturer's protocol. Briefly, trypsinized cells were resuspended in binding buffer with Annexin V-FITC and propidium iodide (PI) and incubated for $15 \mathrm{~min}$ in the dark. Flow cytometry was performed immediately after the staining was completed. All analyses were performed on a Becton Dickinson flow cytometer, and the data were processed using the Cell Quest program.

\section{Transwell chamber assay}

The motility and invasive ability of ECV304 cells were performed in 24-well transwell plates. The upper surface of polycarbonate filters with $8 \mathrm{~mm}$ pores was coated with collagen I. ECV304 cells were pre-incubated with different concentrations of HGF or $1 \%$ BSA (negative control) for $24 \mathrm{~h}$ at $37^{\circ} \mathrm{C}$ in a $\mathrm{CO}_{2}$ incubator and then detached and resuspended in serumfree DMEM. A suspension of cells $\left(2 \times 10^{5}\right.$ cells $\left./ 100 \mu \mathrm{L}\right)$ was placed in the upper chambers, and the lower chambers were filled with $600 \mu \mathrm{L}$ of DMEM medium. Cells were allowed to migrate for $4 \mathrm{~h}$ at $37^{\circ} \mathrm{C}$. Migration was terminated by removing the cells from the upper compartment of the filter with a cotton swab. Cells that had invaded through the collagen I and reached the lower surface of the filter were quantified by counting the cells that migrated in five random microscopic fields per filter at 100×magnification (Olympus IX51; Olympus Corporation, Tokyo, Japan).

\section{Statistical analysis}

All statistical analyses were performed using SPSS10.0 for Windows (SPSS Inc, USA).

Continuous variables were expressed as mean \pm standard deviation (SD), and the differences were evaluated by oneway analysis of variance (ANOVA) or $t$ test.

\section{Results \\ c-Met protein is expressed in ECV304 cells and can be activated by HGF}

To determine whether ECV304 cells express c-Met and whether HGF can activate signal transduction in ECV304 cells, we evaluated the expression of c-Met and phosphor-specific c-Met protein in ECV304 cells. Immunocytochemistry analysis showed ECV304 cells expressed c-Met (receptor of HGF) (Figure 1A). Further, immunoprecipitation followed by Western blot analysis, using antibodies for phosphor-tyrosine and 
A
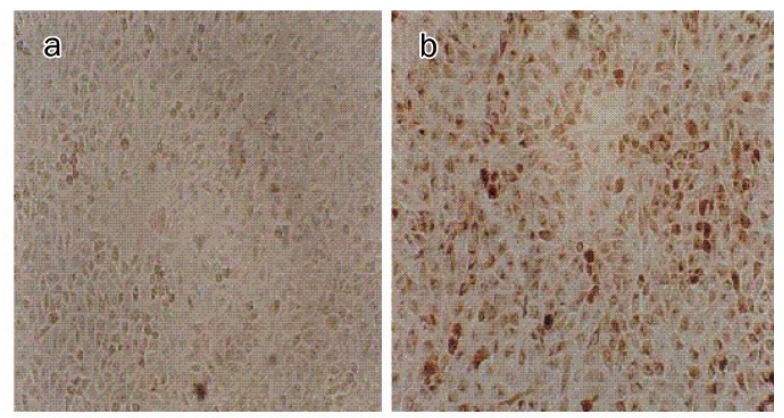

B

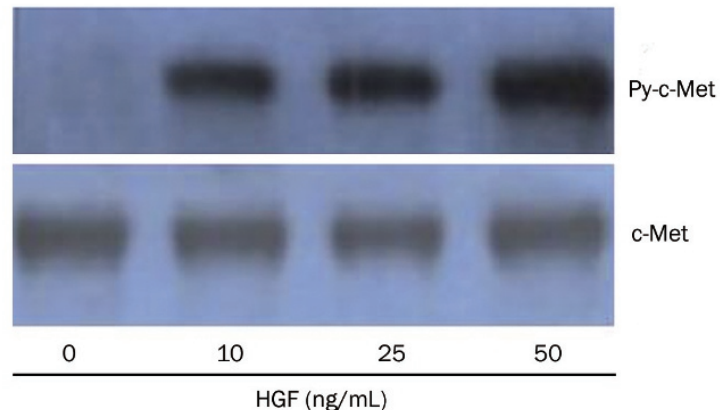

Figure 1. c-Met protein expression and phosphorylation in ECV304 cells. (A) The ECV304 cells were immuocytochemically stained with control antibody(a) and antibody against c-Met(b) (original magnification: 100×). (B) ECV304 cells were treated with HGF at concentrations indicated for 30 min and harvested for immunoprecipitation using c-Met antibody-protein A-agarose conjugates followed by Western blot with phosphotyrosine specific antibody (top: designated as Py-c-Met). Blots were stripped and reported with antibody to c-Met (bottom).

c-Met, revealed that HGF elicited tyrosine phosphorylation of c-Met in ECV304 cells (Figure 1B).

Gamma ray irradiation effects on proliferation, apoptosis and motility of ECV304 cells is dose dependent

Gamma rays can cause the decline of viable cells and inhibit cell proliferation. We detected the proliferation and apoptosis of ECV304 cells using MTT assay and flow cytometry $48 \mathrm{~h}$ after irradiation with single dose of 5, 10, and 20 Gy of gamma rays, respectively. As shown in Figure 2A, the proliferation of ECV304 cells were inhibited after a single irradiation with gamma rays, but irradiation aggravated apoptosis of ECV304 cells and was dose-dependent manner (Figure 2B).

Further, $48 \mathrm{~h}$ post-irradiation, we evaluated the motility and invasive ability of ECV304 cells migrating through collagen I coated membrane. Migrated cells were treated with irradiation of a single dose gamma ray of 5, 10, and $20 \mathrm{~Gy}$, respectively. At $48 \mathrm{~h}$ post-irradiation, cells were placed on collagen I-coated filters and incubated for $4 \mathrm{~h}$ for migration assay. They were then fixed, stained with $0.5 \%$ crystal violet and photographed. The number of cells passing through the filter was counted after staining with crystal violet. The transwell chamber assay showed that the migration ability of ECV304 cells was significantly decreased following a single dose of gamma rays and was dose dependent. The numbers of cells migrat-
A

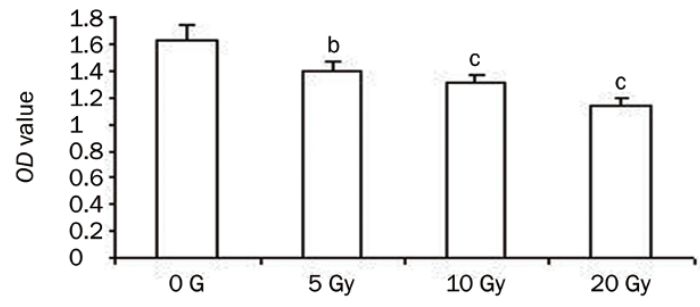

B

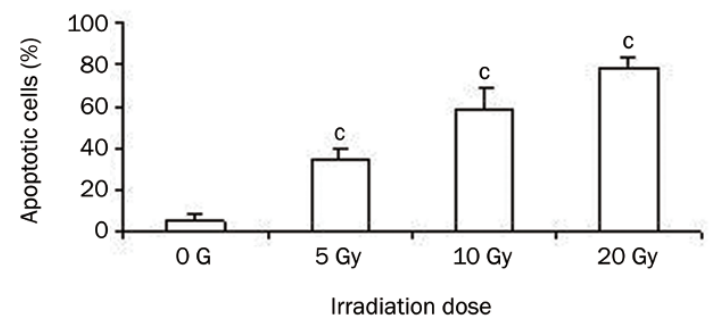

C

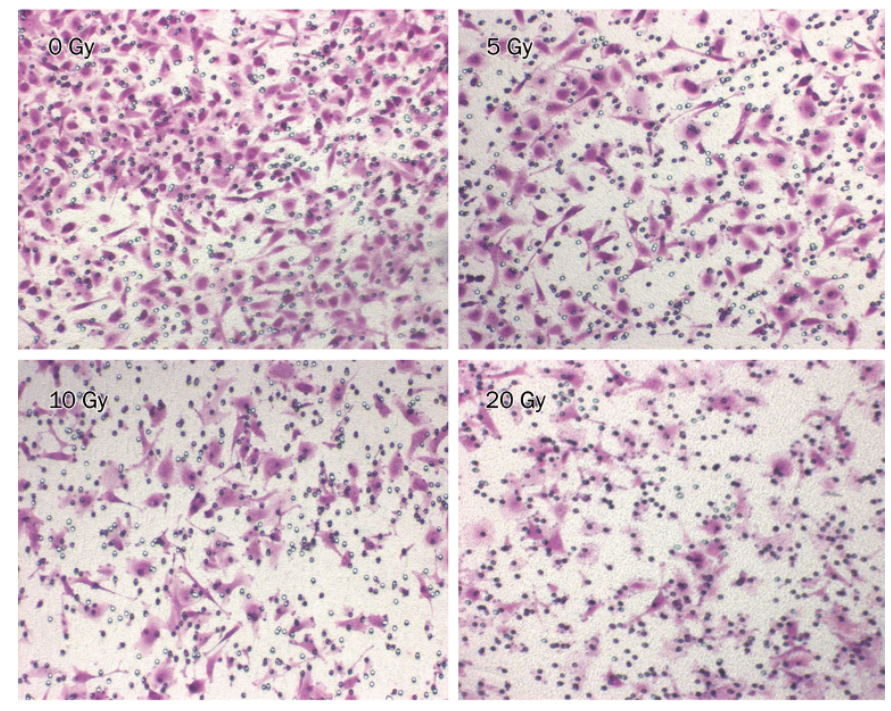

D

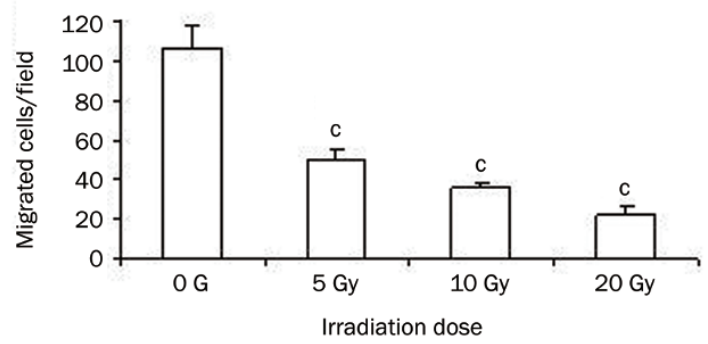

Figure 2. Gamma ray irradiation induces the apoptosis and inhibits proliferation and motility of ECV304 cells. (A) MTT assay shows That gamma ray irradiation inhibits proliferation of ECV304 cells in a dosedependent manner. (B) Apoptosis assay with flow cytometry shows irradiation increases apoptosis of ECV304 cells. (C and D) Depression of ECV304 cell invasion and migration induced by gamma ray irradiation. Typical micrographs of invading ECV304 cells (C) (original magnification: $200 \times$ ). Irradiation decreased rates of cell invasion significantly in a dose dependent manner (D). 0 Gy: sham-irradiated, 5 Gy: irradiated with 5 Gy gamma ray, 10 Gy: irradiated with 10 Gy gamma ray, 20 Gy: irradiated with 20 Gy gamma ray. ${ }^{b} P<0.05,{ }^{\circ} P<0.01$ vs without irradiation. 
ing across the collagen I coated membrane were significantly decreased compared to control cells (Figure 2C-2D).

\section{HGF protects ECV304 against gamma ray irradiation induced damage}

To determine whether HGF protects ECV304 cell against irradiation, cells were incubated with HGF with a dose of 0, 20, or $40 \mathrm{ng} / \mathrm{mL} 3 \mathrm{~h}$ prior to irradiation with $20 \mathrm{~Gy}$ of gamma ray. At $48 \mathrm{~h}$ post-irradiation, the proliferation, apoptosis and migration ability of ECV304 cells were measured. MTT assay confirmed that the proliferation of cells with HGF was decreased compared to sham-irradiated cells, but proliferation was increased significantly compared to irradiated cells without HGF (Figure 3A). Apoptosis analysis with flow cytometry showed that HGF inhibited the apoptosis of irradiated ECV304 cells (Figure 3B).

One of the earliest steps in angiogenesis is the invasion of the basement membrane and migration of endothelial cells toward the angiogenic stimulants. In this study, we observed the effect of HGF on the migratory ability of ECV304 cells. Cells were incubated with HGF with a dose of 0,20 , or 40 $\mathrm{ng} / \mathrm{mL} 3 \mathrm{~h}$ prior to irradiation with $20 \mathrm{~Gy}$ of gamma ray. At $48 \mathrm{~h}$ after irradiation, transwell chamber assay confirmed that the invasive and migratory ability of ECV304 cells was significantly increased by $3 \mathrm{~h}$ pre-incubation with HGF compared to without HGF (Figure 3C-3D).

\section{Discussion}

This study demonstrates that HGF may attenuate irradiationinduced damage of endothelial cells, thereby reducing the apoptosis and improving the proliferation and migration ability of endothelial cells.

As to pathogenesis of RIHD, some studies illustrate that myocardial degeneration and diffused fibrosis are preceded by irradiation-induced damage to the capillary network. Early morphological alterations in irradiated endothelial cells in vivo are irreversible and are followed by a persistent decrease in capillary density. Systematic morphometric studies in rats showed that the reduction of capillary volume, length and density sets in at about 20 days after heart irradiation, and its progress is dose dependent. Simultaneous with capillary rarefication is a focal loss of the endothelial cell marker enzyme alkaline phosphatase that increases with time. When the foci of myocardial degeneration developed, they were invariably situated within the areas of enzyme loss ${ }^{[9,25]}$. Loss of enzyme activity was associated with foci of myocardial degeneration, supporting the hypothesis that lesions were secondary to vascular endothelial cells injury ${ }^{[9]}$.

HGF has mitogenic, morphogenic, and anti-apoptotic activities in a wide variety of cells. The potent activity of HGF to prevent cell death in distinct types of cells has been documented $^{[26-28]}$. HGF has been shown to be released in response to myocardial ischemia-reperfusion injury ${ }^{[2]}$ and acute myocardial ischemia-reperfusion ${ }^{[30,31]}$. It has been postulated that HGF serves as a cardioprotective agent in the heart ${ }^{[32]}$. Some of the cardioprotective effects of HGF may be due to its abil-
A

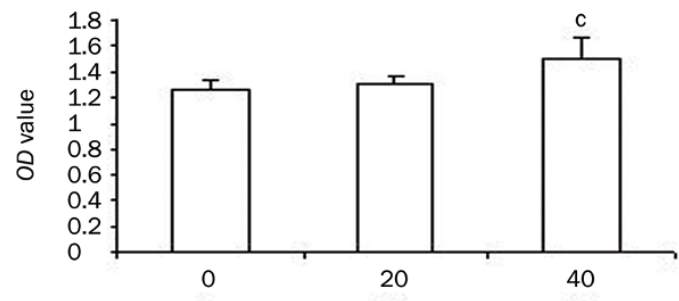

B

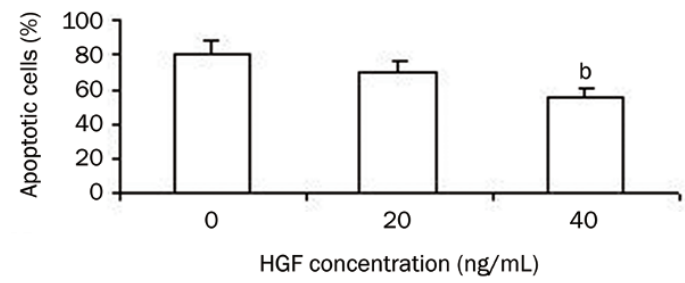

C
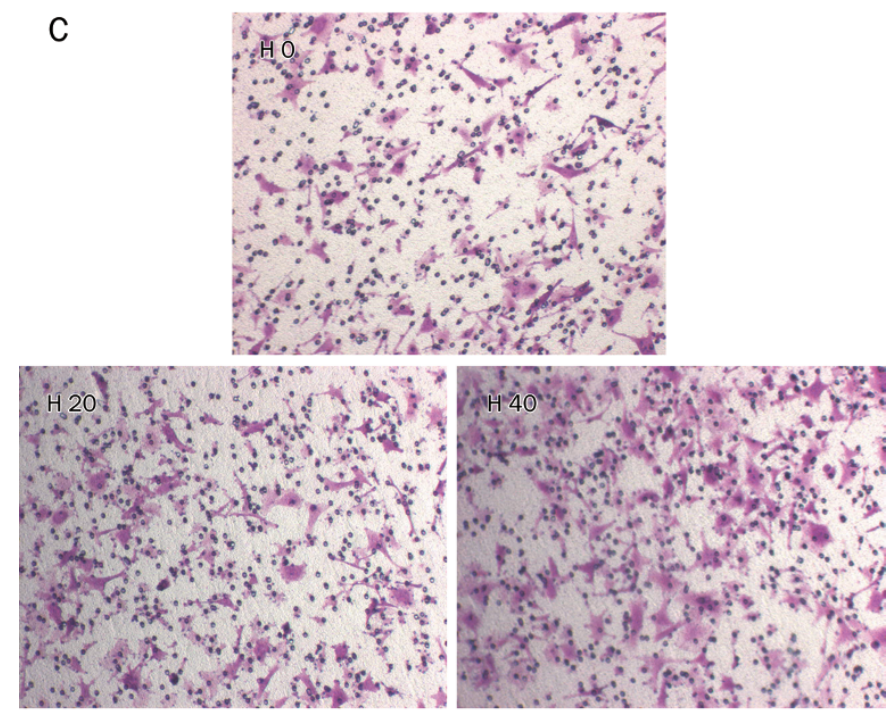

D

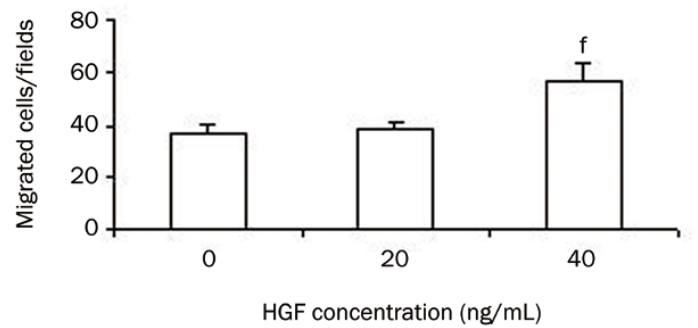

Figure 3. HGF protects ECV304 cells against irradiation of 20 Gy of gamma ray irradiation. (A) Proliferation of cells with HGF (40 ng/mL) was significantly increased compared to cells without HGF. (B) HGF attenuates the apoptosis of ECV304 cells. (C) Typical micrographs of invading ECV304 cells with different concentration of HGF. (D) HGF significantly increased the number of migrating cell at the concentration of $40 \mathrm{ng} / \mathrm{mL}$. HO: without HGF, H20: with HGF (20 ng/mL), H40: with HGF (40 ng/mL). ${ }^{\mathrm{b}} P<0.05,{ }^{\mathrm{c}} P<0.01$ vs group without HGF.

ity to induce angiogenesis by acting on vascular endothelial cells $^{[33]}$.

Radiation injury to endothelial cells of the myocardial capil- 
lary network is the underlying cause of myocardial degeneration and heart failure after heart irradiation. In this study, the HGF receptor c-Met has been shown to be expressed in endothelial cells. We also found that c-Met can function through HGF-induced rapid tyrosine phosphorylation. Therefore, HGF can transmit signals that may protect endothelial cells against irradiation.

In this study, we irradiated ECV304 cells with gamma rays and found that gamma rays damaged the proliferation and migratory ability of ECV304 cells in a dose-dependent manner. Further, cells were incubated with HGF of different concentrations prior to irradiation. HGF was proven to increase the proliferation and inhibit the apoptosis of endothelial cells. We further evaluated the motility and invasive ability of endothelial cells. The invasive and migratory ability of ECV304 cells was significantly increased by $3 \mathrm{~h}$ pre-incubation with HGF prior to irradiation.

One of the earliest steps in angiogenesis is the invasion of the basement membrane and migration of endothelial cells toward the angiogenic stimulants. Angiogenesis is associated with viability and migratory ability of endothelial cells. This study demonstrated that HGF can attenuate radiation injury to endothelial cells, so these experimental results can lay a solid foundation for HGF therapy of irradiation-induced heart disease.

In summary, the present study demonstrates that endothelial cells have functional HGF/c-Met signaling machinery that exhibits phosphorylation of c-Met. Furthermore, the results of this study show that HGF can inhibit the apoptosis and promote the proliferation and motility of endothelial cells. HGF may be useful as a pharmacological agent to treat RIHD.

\section{Acknowledgements}

This project was supported in part by grants from International Atomic Energy Agency program (contract № 13305/ R1) from National Mega-project of Science Research of China (No 2009ZX09503-019) and from China Postdoctoral Science Foundation (№ 20080441309).

\section{Author contribution}

Hua WANG and Li-sheng WANG designed the research; Shun-ying HU, Hai-feng DUAN, Qing-fang LI, Yue-feng YANG and Jin-long CHEN performed the research. Shunying $\mathrm{HU}$ analyzed data and wrote the paper.

\section{References}

1 Stewart JR, Fajardo LF, Gillette SM, Constine LS. Radiation injury to the heart. Int J Radiat Oncol Biol Phys 1995; 31: 1205-11.

2 Schultz-Hector S, Sund M, Thames HD. Fractionation response and repair kinetics of radiation-induced heart failure in the rat. Radiother Oncol 1992; 23: 33-40.

3 Gustavsson A, Eskilsson J, Landberg T, Svahn-Tapper G, White T, Wollmer $\mathrm{P}$, et al. Late cardiac effect after mantle radiotherapy in patients with Hodgkin's disease. Ann Oncol 1990; 1: 355-63.

4 Hancock SL, Donaldson SS, Hoppe RT. Cardiac disease following treatment of Hodgkin's disease in children and adolescents. J Clin Oncol 1993; 11: 1208-15.
5 Reinders JJ, Heijmen BJ, Olofsen-van Acht MJ, van Putten WL, Levendag PC. Ischemic heart disease after mantlefield irradiation for Hodgkin's disease in long-term follow-up. Radiother Oncol 1999; 51: 35-42.

6 Early Breast Cancer Trialist's. Favorable and unfavorable effects on long-term survival of radiotherapy for early breast cancer: an overview of the randomized trials. Lancet 2000; 355: 1757-70.

7 Swerdlow AJ, Higgins CD, Smith P, Cunningham D, Hancock BW, Horwich A, et al. Myocardial infarction mortality risk after treatment for Hodgkin disease: a collaborative British cohort study. J Natl Cancer Inst 2007; 99: 206-14.

8 Fajardo LF, Stewart JR. Experimental radiation-induced heart disease. Light microscopic studies. Am J Pathol 1970; 59: 299-316.

9 Lauk S. Endothelial alkaline phosphatase activity loss as an early stage in the development of radiation-induced heart disease in rats. Radiat Res 1987; 110: 118-28.

10 Jaenke RS, Robbins MEC, Bywaters T, Whitehouse E, Rezvani M, Hopewell JW. Capillary endothelium. Target site if renal radiation injury. Lab Invest 1993; 68: 396-405.

11 Lauk S, Kiszel Z, Buschmann J, Trott KR. Radiation-induced heart disease in rats. Int J Radiat Oncol Biol Phys 1985; 11: 801-8.

12 Schultz-Hector S, Balz K. Radiaton-induced loss of endothelial alkaline phosphatase activity and development of myocardial degeneration. An ultrastructural study. Lab Invest 1994; 71: 25260.

13 Boerma M, Kruse JJ, van Loenen M, Klein HR, Bart Cl, Zurcher C, et al. Increased deposition of von Willebrand factor in the rat heart after local ionizing irradiation. Strahlenther Onkol 2004; 180: 109-16.

14 Wondergem J, van der Laarse A, van Ravels FJ, van Wermeskerken AM, Verhoeve HR, de Graaf BW, et al. In vitro assessment of cardiac performance after irradiation using an isolated working rat heart preparation. Int J Radiat Biol 1991; 59: 1053-68.

15 Franken NA, Camps JA, van Ravels FJ. Comparison of in vivo cardiac function with ex vivo cardiac performance of the rat heart after thoracic irradiation. Br J Radiol 1997; 70: 1004-9.

16 Aoyama T, Takimoto Y, Pennica D, Inoue R, Shinoda E, Hattori R, et al. Augmented expression of cardiotrophin-1 and its receptor component, gp130, in both left and right ventricles after myocardial infarction in the rat. T Mol Cell Cardiol 2000; 32: 1821-30.

17 Schneider MD, Schwartz RJ. Chips ahoy: gene expression in failing hearts surveyed by high-density microarrays. Circulation 2000; 102: 3026-7.

18 Peterson D, Ju H, Hao J, Chapman DC, Dixon IM. Expression if Gia2 and Gsa in myofibroblasts localized to the infarct scar in heart failure due to myocardial infarction. Cardiovasc Res 1998; 41: 575-85.

19 Zarnegar R, Michalopoulos GK. The many faces of hepatocyte growth factor: from hepatopoiesis to hematopoiesis. J cell Biol 1995; 129: 1177-80.

20 Mizuno S, Matsumoto K, Nakamura T. HGF as a renotrophic and antifibrotic regulator in chronic renal disease. Front Biosci 2008; 13: 7072-86.

21 Birchmeier C, Gherardi E. Developmental roles of HGF/SF and its receptor, the c-Met tyrosine kinase. Trends Cell Biol 1998; 8: 40410.

22 Bussolino F, Di Renzo MF, Ziche M, Bocchietto E, Olivero M, Naldini $\mathrm{L}$, et al. Hepatocyte growth factor is a potent angiogenic factor which stimulates endothelial cell motility and growth. J Cell Biol 1992; 119: 629-41.

23 van Belle E, Witzenbichler B, Chen D, Silver M, Chang L, Schwall R, et al. Potentiated angiogenic effect of scatter factor/hepatocyte growth factor via induction of vascular endothelial growth factor: the case 
for paracrine amplification of angiogenesis. Circulation 1998; 97 : 381-90.

24 Anki M, Morishta R, Taniyama Y, Kida I, Moriguchi A, Matsumoto K, et al. Angiogenesis induced by hepatocyte growth factor in non-infarcted myocardium and infracted myocardium; up-regulation of essential transcription factor for angiogenesis, ets. Gene Ther 2000; 7: 41727.

25 Fajardo LF, Stewart JR. Pathogenesis of radiation-induced myocardial fibrosis. Lab Invest 1973; 29: 244-57.

26 Hu SY, Qiu L, Duan HF, Wang H, Wang RL, Guo ZK, et al. Hepatocyte growth factor protects cultured rat cardiomyocytes against apoptosis induced by gamma ray irradiation. Med J Chin People Liberation Army 2007, 32: 482-4. Chinese.

27 Yo Y, Morishita R, Nakamura S, Tomita N, Yamamoto K, Moriguchi A, et al. Potential role of hepatocyte growth factor in the maintenance of renal structure: anti-apoptotic action of HGF on the epithelial cells. Kidney Int 1998; 54: 1128-38.

28 Kosai K, Matsumoto K, Nakamura T. Hepatocyte growth factor prevents endotoxin-induced lethal hepatic failure in mice. Hepatology 1999; 30: 151-9.

29 Ono K, Matsumori A, Shioi T, Furukawa Y, Sasayama S. Enhanced expression of hepatocyte growth factor/c-Met by myocardial ischemia and reperfusion in a rat model. Circulation 1997; 95: 2552-8.

30 Matsumori A, Furukawa Y, Hashimoto T, Ono K, Shioi T, Okada M, et al. Increased circulating hepatocyte growth factor in the early stage of acute myocardial infarction. Biochem Biophys Res Commun 1996; 221: 391-5.

31 Sato T, Yoshinouchi T, Sakamoto T, Fujieda H, Murao S, Sato H, et al. Hepatocyte growth factor(HGF): a new biochemical marker for acute myocardial infarction. Heart Vessels 1997; 12: 241-6.

32 Schaper W, Kubin T. Is hepatocyte growth factor a protein with cardioprotective activity in the ischemic heart? Circulation 1997; 95: 2471-2.

33 Grant DS, Kleinman HK, Goldberg ID, Bhargava MM, Nickoloff BJ, Kinsella JL, et al. Scatter factor induces blood vessel formation in vivo. Proc Natl Acad Sci USA 1993; 90: 1937-41. 